\title{
Plasmid-borne 16S rRNA methylase ArmA in aminoglycoside-resistant Klebsiella pneumoniae in Poland
}

Correspondence

Rafał Gierczyński

rgierczynski@pzh.gov.pl

Received 8 July 2010

Accepted 16 January 2011

\author{
Katarzyna Zacharczuk, ${ }^{1}$ Katarzyna Piekarska, ${ }^{1}$ Jolanta Szych, ${ }^{1}$ \\ Marek Jagielski, ${ }^{1}$ Laura Hidalgo, ${ }^{2}$ Álvaro San Millán, ${ }^{2}$ Belén Gutiérrez, ${ }^{2}$ \\ Waldemar Rastawicki, ${ }^{1}$ Bruno González-Zorn ${ }^{2}$ and Rafał Gierczyński ${ }^{1}$ \\ ${ }^{1}$ Department of Bacteriology, National Institute of Public Health - National Institute of Hygiene, \\ Chocimska 24, 00-791 Warsaw, Poland \\ ${ }^{2}$ Departamento de Sanidad Animal, Facultad de Veterinaria and VISAVET (Centro de Vigilancia \\ Sanitaria Veterinaria), Universidad Complutense de Madrid, 28040 Madrid, Spain
}

\section{INTRODUCTION}

Acquisition of multidrug resistance (MDR) by members of the Enterobacteriaceae, especially panaminoglycosideresistant Klebsiella pneumoniae, has become a global concern. Aminoglycosides are commonly used to treat severe bacterial infections, often in combination with $\beta$ lactams (Mingeot-Leclercq et al., 1999). Initially, production of aminoglycoside-modifying enzymes and a decrease in intracellular antibiotic accumulation were considered predominant mechanisms conferring resistance to aminoglycosides. The substitution of ribosomal proteins or mutation of rRNA were less commonly reported. In recent years, the emergence of panaminoglycoside-resistant bacteria producing plasmid-borne $16 \mathrm{~S}$ rRNA methylases has been increasingly reported (Fritsche et al., 2008). The methylases confer resistance to 4,6-disubstituted deoxystreptamines. This group encompasses the majority of aminoglycosides used in therapy (kanamycin, amikacin, gentamicin, netilmicin, tobramycin). Up to now, six $16 \mathrm{~S}$ rRNA methylases have been described: ArmA, RmtA, RmtB, RmtC, RmtD and NpmA (Doi et al., 2008). It is noteworthy that NpmA confers resistance not only to 4,6-disubstituted deoxystreptamines but also to 4,5-disubstituted 2-deoxystreptamines, including neomycin and ribostamycin (Wachino et al., 2007).

Abbreviations: ESBL, extended-spectrum $\beta$-lactamase; RFLP, restriction fragment length polymorphism.
ArmA (aminoglycoside resistance methyltransferase) was the first $16 \mathrm{~S}$ rRNA methylase reported in a clinical isolate of $K$. pneumoniae (Galimand et al., 2003). It was found in France in 2003. The armA gene encoding the methylase was detected in a composite transposon, Tn 1548 , located in a conjugative plasmid of approximately $90 \mathrm{~kb}$ (Galimand et al., 2005). Nowadays, ArmA predominates in 16S rRNA methylase-producing members of the Enterobacteriaceae in Europe and is reported worldwide (Fritsche et al., 2008). Although, the highest incidence $(1.8 \%)$ of ArmA-producing strains in Europe has been reported in Bulgaria (Sabtcheva et al., 2008), the incidence continues to increase in the world. Recently, $3 \%$ of clinical isolates of $K$. pneumoniae in China were reported to carry the $\operatorname{arm} A$ gene (Wu et al., 2009). The aim of this study was to determine the diversity of ArmA-producing K. pneumoniae in Poland. In addition, we identified a plasmid vector conferring ArmA production, and investigated the genetic environment surrounding the armA gene.

\section{METHODS}

Bacterial isolates. We conducted a retrospective screening of the $16 \mathrm{~S}$ rRNA methylase-producing isolates in our stock of $K$. pneumoniae from hospitals and sanitary-epidemiological stations in Poland. This stock encompassed nearly 500 isolates of $K$. pneumoniae from a number of laboratories in the country. No epidemiological link was known for the majority of the isolates. Records of resistance 
profiles to aminoglycosides for nearly 300 isolates collected during the last 10 years (from April 2000 to May 2010) were screened in this study. In total, 34 isolates resistant to at least two aminoglycosides of the 4,6-disubstituted deoxystreptamines were found. Isolates resistant to a single agent were ignored. All the 34 isolates of $K$. pneumoniae were recovered from the stock and were reidentified by classical biochemical tube tests. ArmA-producing Escherichia coli with plasmid pMUR050 (González-Zorn et al., 2005) and E. coli strain $\Delta 32 / 01$ with armA in a large (approx. $90 \mathrm{~kb}$ ) conjugative plasmid of the pCTX-M3 family were used as positive controls for 16S rRNA methylase production (Gierczyński et al., 2003; Zacharczuk et al., 2011).

Screening for 16S rRNA methylase-producing isolates. All 34 isolates were spread onto Mueller-Hinton agar supplemented with amikacin and kanamycin each at a concentration of $64 \mu \mathrm{g} \mathrm{ml}^{-1}$.

Detection of resistance genes and the genetic environment of armA. Genes armA, rmtA, rmtB, rmtC, rmtD and $n p m A$ encoding major 16S rRNA methylases were detected by PCR using primers and conditions described previously (Fritsche et al., 2008). For the $16 \mathrm{~S}$ rRNA methylase-producing isolates, amplification of extendedspectrum $\beta$-lactamase (ESBL)-encoding genes was performed with previously described primers (Dzierżanowska et al., 2010) for bla $a_{\mathrm{TEM}}$, $b l a_{\mathrm{SHV}}$ and $b l a_{\mathrm{CTX}-\mathrm{M}}$. PCR mapping was conducted as described by Zhang et al. (2008). IncF and IncR primers described by Galimand et al. (2005) were used to detect plasmids of the IncL/M incompatibility group. DNA sequencing of PCR products was conducted for both the DNA strands as previously described (Gierczyński et al., 2004). All the PCR tests were conducted in triplicate.

Susceptibility testing of 165 rRNA methylase-producing isolates. The MICs of gentamicin, amikacin, kanamycin, neomycin and streptomycin were determined for the $16 \mathrm{~S}$ rRNA methylase-producing isolates by a serial double-dilution method in accordance with published recommendations (CLSI, 2008). E. coli with pMUR050 and Salmonella enterica serovar Oranienburg 32/01 were used as aminoglycosideresistant controls. E. coli ATCC 25922 was used as a susceptible control for susceptibility testing.

Plasmid extraction and Southern blot hybridization analysis. A NucleoBond PC20 kit (Machery-Nagel) was used to extract plasmids from isolates producing $16 \mathrm{~S}$ rRNA methylase. To investigate the $\operatorname{armA}$ gene localization, the purified total plasmids were separated on a $1.0 \%$ agarose gel (Prona Plus), then subjected to Southern blotting and hybridization with a probe specific for the armA gene. The purified total plasmids were also digested using the ClaI endonuclease equivalent Bsu15I (Fermentas Life Science) as recommended by the manufacturer. Restriction fragments were electrophoresed on a $1.5 \%$ agarose gel (Prona Plus). The resulting restriction fragment length polymorphism (RFLP) patterns were analysed by Southern blotting with the armA probe.

For Southern blot hybridization, plasmids or the RFLP patterns were transferred from electrophoretic gels to Nylonbind B membrane (SERVA Electrophoresis) and then hybridized with the armA gene specific probe. Probe labelling, hybridization and detection were carried out with a DIG High Prime DNA Labelling and Detection starter kit I (Roche Diagnostics) according to the manufacturer's instructions. Southern blot hybridization experiments were performed twice.

PFGE genotyping. To determine the genetic relatedness of the ArmA-producing K. pneumoniae isolates in Poland, we carried out PFGE. PFGE was conducted as described previously (Dzierżanowska et al., 2010) using the CHEF-DR II system (Bio-Rad Laboratories) and endonuclease $\mathrm{XbaI}$ (Fermentas Life Science) with a switching time of 3-30 s for $24 \mathrm{~h}$ at $14{ }^{\circ} \mathrm{C}$ and voltage gradient of $6.0 \mathrm{~V} \mathrm{~cm}{ }^{-1}$.
PFGE patterns were analysed using the GelCompar II version 5.10 software (Applied Maths). Similarity clustering analyses were performed using UPGMA and the Dice correlation coefficient with a tolerance of $1.2 \%$. PFGE genotyping was performed twice.

\section{RESULTS}

\section{Potential 16S rRNA methylase producers}

Among the $34 \mathrm{~K}$. pneumoniae isolates screened, 17 grew on the selective Mueller-Hinton agar with amikacin and kanamycin. This result suggested potential 16S rRNA methylase activity in these 17 isolates. All these isolates were characterized in Table 1.

\section{Aminoglycoside resistance profiles}

The 17 isolates resistant to amikacin and kanamycin had elevated MICs (see Table 1) to all of the 4,6-disubstituted deoxystreptamines used in the study. The MIC range was high (256-1024 $\mathrm{mg} \mathrm{l}^{-1}$ ) and was comparable to MIC ranges reported elsewhere for $16 \mathrm{~S}$ rRNA methylaseproducing K. pneumoniae (Bogaerts et al., 2007).

\section{Screening of 165 rRNA methylase genes}

All the 17 isolates resistant to amikacin and kanamycin were positive for the armA gene by PCR testing. No PCR products for $r m t A, r m t B, r m t C, r m t D$ and $n p m A$ genes were detected in the tested isolates. DNA-sequencing analysis of the PCR products of two randomly selected isolates revealed $100 \%$ nucleotide identity to the armA gene of K. pneumoniae strain BM4536 (GenBank accession no. AY220558).

\section{Screening of bla genes for the major $\beta$-lactamases}

All the armA-positive isolates also carried the $b l a_{\mathrm{CTX}-\mathrm{M}}$ gene for an ESBL of the CTX-M-type family (Table 1). DNA sequencing of the $b l a_{\text {CTX-M gene using primers }}$ described previously (Gierczyński et al., 2003) revealed that isolates 474/02 and DM0342 produced a CTX-M-3 ESBL. These isolates also carried the bla gene for a TEM-type $\beta$ lactamase. Eleven of the armA-positive isolates were also positive in the PCR with primers for the $b l a_{\mathrm{SHV}}$ gene for an SHV-type enzyme (Table 1). The PCR product for IncL/M plasmids was detected in all ArmA-producing isolates of $K$. pneumoniae apart from 31/03 (Table 1).

\section{Exploration of the regions surrounding the armA gene}

PCR mapping experiments revealed that the armA gene and its flanking regions in all $17 \mathrm{~K}$. pneumoniae isolates producing ArmA were in the same order and direction as in transposon Tn1548 found in K. pneumoniae in France 
Table 1. Characterization of $17 \mathrm{~K}$. pneumoniae isolates producing $16 \mathrm{~S}$ rRNA methylase ArmA

\begin{tabular}{|c|c|c|c|c|c|c|c|c|c|c|c|c|c|c|}
\hline \multirow[t]{2}{*}{ Isolate } & \multirow{2}{*}{$\begin{array}{l}\text { Year of } \\
\text { isolation }\end{array}$} & \multicolumn{2}{|c|}{ Origin } & \multicolumn{5}{|c|}{$\operatorname{MIC}\left(\mathrm{mg} \mathrm{l}^{-1}\right)$ of $^{\star}$} & \multicolumn{4}{|c|}{$\mathrm{PCR} \dagger$} & \multirow{2}{*}{$\begin{array}{c}\text { Plasmid } \\
\text { profile }\end{array}$} & \multirow{2}{*}{$\begin{array}{l}\text { PFGE } \\
\text { cluster }\end{array}$} \\
\hline & & City & Hospital & GEN & AMK & KAN & STR & NEO & CTX-M & TEM & SHV & IncL/M & & \\
\hline $468 / 02$ & 2002 & Łódź & $\mathrm{H} 4$ & $>1024$ & $>1024$ & $>1024$ & 2 & 16 & + & + & + & + & A & A \\
\hline $473 / 02$ & 2002 & Łódź & $\mathrm{H} 1$ & $>1024$ & $>1024$ & $>1024$ & 2 & 16 & + & + & + & + & A & B \\
\hline $474 / 02$ & 2002 & Łódź & $\mathrm{H} 1$ & $>1024$ & $>1024$ & $>1024$ & 4 & 32 & + & + & + & + & A & B \\
\hline $475 / 02$ & 2002 & Łódź & $\mathrm{H} 1$ & $>1024$ & $>1024$ & $>1024$ & 2 & 16 & + & + & + & + & $\mathrm{B}$ & B \\
\hline $477 / 02$ & 2002 & Łódź & H1 & $>1024$ & $>1024$ & $>1024$ & 4 & 32 & + & + & + & + & A & $\mathrm{B}$ \\
\hline $478 / 02$ & 2002 & Łódź & $\mathrm{H} 1$ & $>1024$ & $>1024$ & $>1024$ & 2 & 16 & + & + & + & + & B & $\mathrm{B}$ \\
\hline $2 / 03$ & 2003 & ND & ND & 512 & $>1024$ & $>1024$ & 2 & 16 & + & + & + & + & $\mathrm{C}$ & NA \\
\hline $12 / 03$ & 2003 & Łódź & H3 & $>1024$ & $>1024$ & $>1024$ & 2 & 16 & + & + & + & + & $\mathrm{D}$ & A \\
\hline $14 / 03$ & 2003 & Łódź & H3 & $>1024$ & $>1024$ & $>1024$ & 2 & 8 & + & + & + & + & B & A \\
\hline $30 / 03$ & 2003 & Łódź & $\mathrm{H} 2$ & $>1024$ & $>1024$ & $>1024$ & 4 & 128 & + & + & + & + & E & $\mathrm{C}$ \\
\hline $31 / 03$ & 2003 & Łódź & $\mathrm{H} 2$ & 256 & $>1024$ & $>1024$ & 2 & 32 & + & + & - & - & E & $\mathrm{C}$ \\
\hline $177 / 03$ & 2003 & ND & $\mathrm{ND}$ & $>1024$ & $>1024$ & $>1024$ & 2 & 16 & + & + & + & + & $\mathrm{F}$ & NA \\
\hline DM0265 & 2009 & Warsaw & $\mathrm{H} 1$ & $>1024$ & $>1024$ & $>1024$ & 16 & 256 & + & + & - & + & G & $\mathrm{D}$ \\
\hline DM0266 & 2009 & Warsaw & $\mathrm{H} 1$ & $>1024$ & $>1024$ & $>1024$ & 16 & 256 & + & + & - & + & $\mathrm{H}$ & $\mathrm{D}$ \\
\hline DM0269 & 2009 & Warsaw & $\mathrm{H} 1$ & $>1024$ & $>1024$ & $>1024$ & 16 & $>512$ & + & + & - & + & G & $\mathrm{D}$ \\
\hline DM0270 & 2009 & Warsaw & $\mathrm{H} 1$ & $>1024$ & $>1024$ & $>1024$ & 16 & 256 & + & + & - & + & I & $\mathrm{D}$ \\
\hline DM0342 & 2010 & Warsaw & $\mathrm{H} 2$ & $>1024$ & $>1024$ & $>1024$ & 32 & 2 & + & + & - & + & A & NA \\
\hline
\end{tabular}

NA, Not assigned; ND, no data. ${ }^{\star}$ GEN, Gentamicin; AMK, amikacin; KAN, kanamycin; STR, streptomycin; NEO, neomycin.

$\dagger$ Results of PCR test for the bla genes encoding $\beta$-lactamases of the CTX-M, TEM and SHV families, and the IncL/M incompatibility group plasmids: + , positive result; - , negative result.

(GenBank accession no. AY220558) and Citrobacter freundii in Poland (GenBank accession no. AF550415).

\section{Plasmid profiles, RFLP patterns and Southern blots}

Fifteen isolates with the armA gene harboured two to six plasmids ranging from 3 to approximately $140 \mathrm{~kb}$. Each of these isolates carried a $\sim 90 \mathrm{~kb}$ plasmid. Two other isolates with the armA gene (30/03 and 31/03) possessed a large single plasmid of $\sim 130 \mathrm{~kb}$ (Fig. 1a). For all 17 isolates, the armA probe hybridized exclusively to the large plasmid of $\sim 90$ or $130 \mathrm{~kb}$. A background hybridization signal was observed for a band of approximately $23 \mathrm{~kb}$ corresponding to fragmented chromosome. Plasmid profiles and the corresponding Southern blots with the armA probe for three genetically unrelated isolates, 474/02, 2/03 and DM0265, are shown in Fig. 1(b). The ClaI (Bsu15I) RFLP patterns of the plasmids extracted from each of the three aforementioned isolates are shown in Fig. 1(c). For the three unrelated isolates, the $\operatorname{armA}$ probe hybridized exclusively with a restriction fragment of approximately $10 \mathrm{~kb}$ in size.

\section{PFGE genotyping}

XbaI-PFGE patterns and a dendrogram of the pattern similarity for all 17 isolates of ArmA-producing $K$. pneumoniae are shown in Fig. 2. Fifteen isolates represented unique PFGE patterns. Two isolates were indistinguishable. Four clonal groups (A, B, C and D) encompassing 14 isolates were distinguished. PFGE profiles of three isolates were distinct and could not be assigned to any of the clusters. Isolates of clusters B, C and D were hospital-specific, while cluster A isolates were specific for the city of Łódź.

\section{DISCUSSION}

K. pneumoniae is one of the major nosocomial pathogens. These bacteria effectively colonize patients as well as hospital personnel and occupy a hospital environment. To survive in this niche, $K$. pneumoniae developed a large variety of resistance traits including production of 16S rRNA methylases with the major representative ArmA (Fritsche et al., 2008). In Europe, this methylase has been reported in $K$. pneumoniae from patients in France (Galimand et al., 2003), Belgium (Bogaerts et al., 2007) and Bulgaria (Sabtcheva et al., 2008). In this study, we characterized 17 isolates of ArmAproducing $K$. pneumoniae in Poland. The isolates were collected from patients in six hospitals in the two most populated cities in the country: Warsaw and Łódź. To the best of our knowledge, this is the first report in which $16 \mathrm{~S}$ rRNA methylase-producing $K$. pneumoniae isolates from various hospitals in Poland have been characterized. However, the ArmA-producing isolates from Warsaw, which we report herein, were also investigated in our recent study on factors conferring co-production of $K$. pneumoniae carbapenemase (KPC-2) and ArmA (Zacharczuk et al., 2011).

In the present study, PFGE genotyping distinguished 16 genotypes among 17 ArmA-producing isolates of $K$. 
(a)
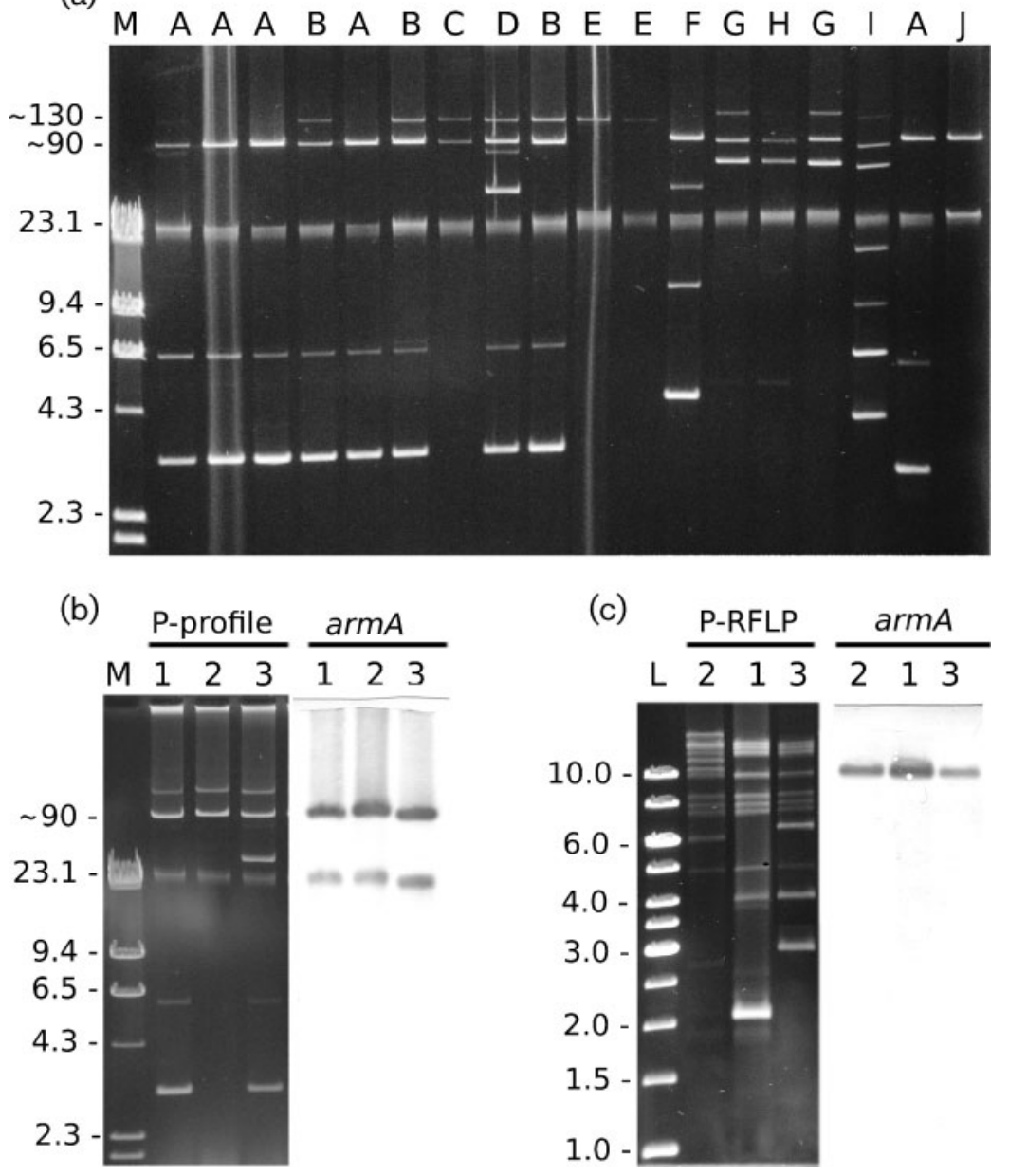

Fig. 1. Electrophoretic patterns and Southern blots with the armA gene specific probe. (a) Plasmid profiles of $17 \mathrm{~K}$. pneumoniae isolates producing ArmA. Designations of the profiles are shown in capital letters above the patterns. Lane J, profile of $E$. coli $\Delta 32 / 01$ with pCTX-M plasmid $\sim 90 \mathrm{~kb}$. (b) Plasmid profiles of three epidemiologically unrelated $K$. pneumoniae isolates and corresponding Southern blots. (c) Bsu15l (Clal) RFLP patterns of the plasmids shown in (b) together with the corresponding Southern blots. Lanes: 1, 2 and $3, K$. pneumoniae isolates 474/02, 2/03 and DM0265M, respectively; M, linear dsDNA ladder - Hindlll digest of the lambda phage (Sigma-Aldrich); L, DNA ladder - GeneRuler $1 \mathrm{~kb}$ Ladder (Fermentas Life Sciences). DNA size is shown in $\mathrm{kb}$.

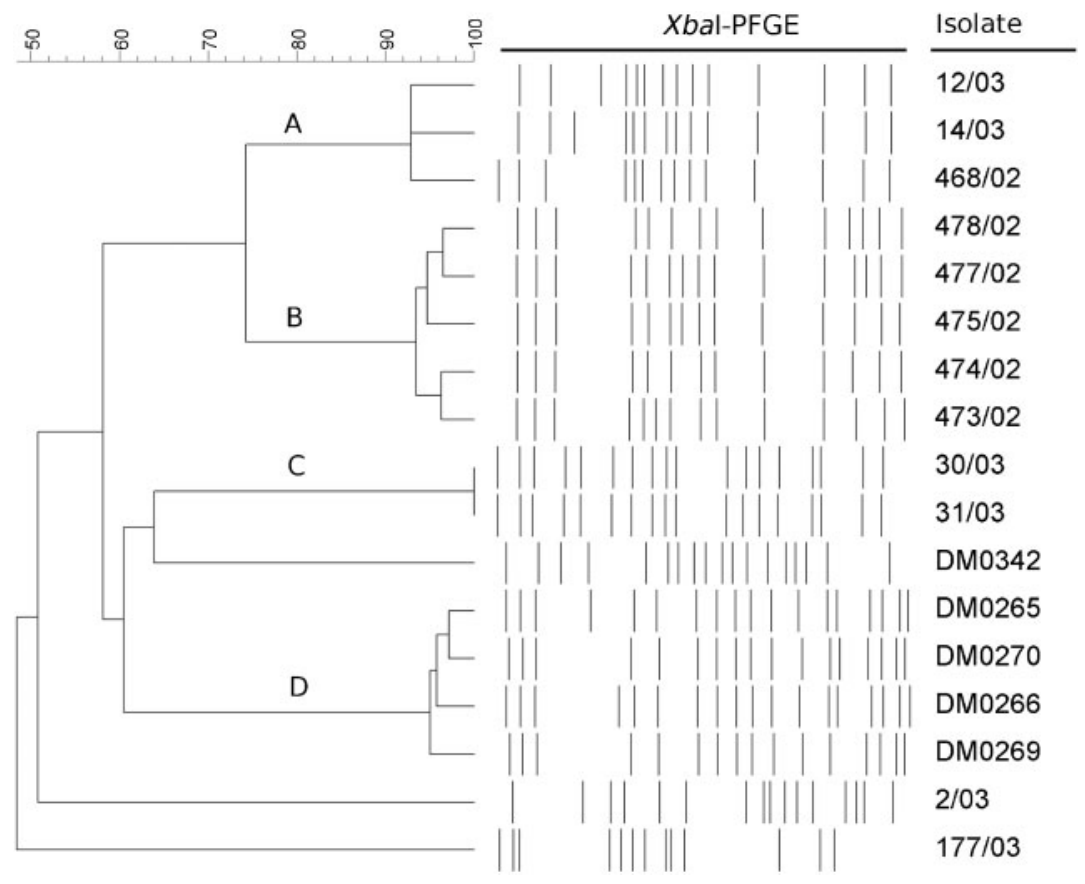

Fig. 2. Dendrogram of ArmA-producing $K$. pneumoniae isolates in Poland. The dendrogram is based on Xbal-PFGE pattern similarity. 
pneumoniae collected during the past decade in Poland. The majority of these isolates were grouped to four PFGE clusters. In general, the PFGE clusters were hospitalspecific. With a single exception, isolates of the same cluster were collected in the same hospital, and were closely related (similarity above $92 \%$ ). These findings may reflect the nosocomial nature of $K$. pneumoniae infections and argue for an effective horizontal transfer of ArmA.

The hybridization experiments revealed that the armA gene was carried on a large $\sim 90 \mathrm{~kb}$ plasmid in the majority of the tested $K$. pneumoniae isolates. However, in two related isolates, $\operatorname{armA}$ was detected on a larger plasmid of $\sim 130 \mathrm{~kb}$. All but one of the ArmA-producing K. pneumoniae isolates carried the IncL/ $\mathrm{M}$ incompatibility group plasmid. The IncL/M plasmids encoding ArmA have been commonly reported for $K$. pneumoniae in France and in Bulgaria (Galimand et al., 2005). Of note, in all the ArmA-producing $K$. pneumoniae isolates, the armA gene was found to be flanked by the same elements as reported previously in transposon Tn1548 (Galimand et al., 2005). Since no difference in the elements adjacent to the $\operatorname{armA}$ gene was found between the 90 and $130 \mathrm{~kb}$ plasmid, this may suggest that $\operatorname{armA}$ has disseminated among K. pneumoniae isolates in Poland on the same transposable structure. Further studies are, however, necessary to elucidate the $\operatorname{arm} A$ gene environment on these two large plasmids.

To characterize the $90 \mathrm{~kb}$ plasmid predominating among ArmA-producing $K$. pneumoniae in Poland, two isolates representative of two main XbaI-PFGE clusters (B and D), together with a third unrelated isolate, were selected for further RFLP and Southern blot experiments. Isolates of cluster B $(n=5)$ were collected in 2002 in Łódź while isolates of cluster D $(n=4)$ were collected in 2009 in Warsaw. The RFLP and Southern blot analysis revealed that the armA gene maps to the same approximately $10 \mathrm{~kb} \mathrm{ClaI} \mathrm{(Bsu15I)}$ restriction fragment of the large plasmid in all the three epidemiologically unrelated $K$. pneumoniae isolates. This finding, together with the results of the transposon mapping, may argue for a relatively conservative structure of the arm $\mathrm{A}$ gene environment in $K$. pneumoniae in Poland. It is noteworthy that the presence of the armA gene in $\operatorname{Tn} 1548$ on a $\sim 90 \mathrm{~kb}$ plasmid (pCTX-M3) was previously reported in C. freundii in Poland (Gołębiewski et al., 2007) and in K. pneumoniae in France (Galimand et al., 2005).

In a recent study, Zacharczuk et al. (2011) transferred by electroporation the $90 \mathrm{~kb}$ plasmid from ArmA-producing K. pneumoniae DM0269 to E. coli DH5 $\alpha$. Interestingly, a large plasmid from recipient strain ETarmA belonged to the IncL/M incompatibility group and its ClaI-RFLP pattern closely resembled that of a large conjugative plasmid from CTX-M-3-producing E. coli transconjugant $\Delta 32 / 01$ that was originally found in strain $32 / 01$ of $S$. Oranienburg isolated in Poland in 2001 (Gierczyński et al., 2003). It is noteworthy that the large plasmids derived from K. pneumoniae DM0269 and S. Oranienburg 32/01 carried the armA gene on a $\sim 10 \mathrm{~kb}$ ClaI restriction fragment (Zacharczuk et al., 2011). These findings strongly support the results of the present study, and may argue for a conservative nature of the large plasmid on which the armA gene is horizontally transferred amongst K. pneumoniae and other Enterobacteriaceae species in Poland.

\section{ACKNOWLEDGEMENTS}

This work was supported by the Ministry of Science and Higher Education of Poland with research grant NN 404 165034. Part of the study was realized in-frame of WP29 of Med.Vet.Net. We thank Yoshichika Arakawa from the Department of Bacterial Pathogenesis and Infection Control, National Institute of Infectious Diseases in Tokyo, Japan, for providing plasmids with reference genes: $\operatorname{armA\text {,}}$ $r m t A, r m t B$ and $r m t C$.

\section{REFERENCES}

Bogaerts, P., Galimand, M., Bauraing, C., Deplano, A., Vanhoof, R., De Mendonca, R., Rodriguez-Villalobos, H., Struelens, M. \& Glupczynski, Y. (2007). Emergence of ArmA and RmtB aminoglycoside resistance $16 \mathrm{~S}$ rRNA methylases in Belgium. I Antimicrob Chemother 59, 459-464.

CLSI (2008). Performance Standards for Antimicrobial Disc Susceptibility Testing, 18th Informational Supplement. CLSI document M100-S18. Wayne, PA: Clinical and Laboratory Standards Institute.

Doi, Y., Wachino, J. \& Arakawa, Y. (2008). Nomenclature of plasmidmediated 16S rRNA methylases responsible for panaminoglycoside resistance. Antimicrob Agents Chemother 52, 2287-2288.

Dzierżanowska, D., Kamińska, W., Semczuk, K., Borowiec, D., Matysiak, M., Szumała-Kakol, A., Gierczyński, R. \& Patzer, J. A. (2010). Carriage of genes for various extended-spectrum $\beta$-lactamases: a novel resistance strategy of Klebsiella pneumoniae in Poland. Int J Antimicrob Agents 35, 392-395.

Fritsche, T. R., Castanheira, M., Miller, G. H., Jones, R. N. \& Armstrong, E. S. (2008). Detection of methyltransferases conferring high-level resistance to aminoglycosides in Enterobacteriaceae from Europe, North America, and Latin America. Antimicrob Agents Chemother 52, 1843-1845.

Galimand, M., Courvalin, P. \& Lambert, T. (2003). Plasmid-mediated high-level resistance to aminoglycosides in Enterobacteriaceae due to 16S rRNA methylation. Antimicrob Agents Chemother 47, 2565-2571.

Galimand, M., Sabtcheva, S., Courvalin, P. \& Lambert, T. (2005). Worldwide disseminated armA aminoglycoside resistance methylase gene is borne by composite transposon Tn1548. Antimicrob Agents Chemother 49, 2949-2953.

Gierczyński, R., Szych, J., Cieślik, A., Rastawicki, W. \& Jagielski, M. (2003). The occurrence of the first two CTX-M-3 and TEM-1 producing isolates of Salmonella enterica serovar Oranienburg in Poland. Int J Antimicrob Agents 21, 497-499.

Gierczyński, R., Kałuzewski, S., Rakin, A., Jagielski, M., Zasada, A., Jakubczak, A., Borkowska-Opacka, B. \& Rastawicki, W. (2004). Intriguing diversity of Bacillus anthracis in eastern Poland - the molecular echoes of the past outbreaks. FEMS Microbiol Lett 239, 235-240.

Gołębiewski, M., Kern-Zdanowicz, I., Zienkiewicz, M., Adamczyk, M., Zylinska, J., Baraniak, A., Gniadkowski, M., Bardowski, J. \& Ceglowski, P. (2007). Complete nucleotide sequence of the pCTXM3 plasmid and its involvement in spread of the extended-spectrum 
$\beta$-lactamase gene bla $a_{\mathrm{CTX}-\mathrm{M}-3 .}$. Antimicrob Agents Chemother 51, 37893795.

González-Zorn, B., Teshager, T., Casas, M., Porrero, M. C., Moreno, M. A., Courvalin, P. \& Domínguez, L. (2005). armA and aminoglycoside resistance in Escherichia coli. Emerg Infect Dis 11, 954-956.

Mingeot-Leclercq, M. P., Glupczynski, Y. \& Tulkens, P. M. (1999). Aminoglycosides: activity and resistance. Antimicrob Agents Chemother 43, 727-737.

Sabtcheva, S., Saga, T., Kantardjiev, T., Ivanova, M., Ishii, Y. \& Kaku, M. (2008). Nosocomial spread of armA-mediated high-level aminoglycoside resistance in Enterobacteriaceae isolates producing CTX-M-3 $\beta$-lactamase in a cancer hospital in Bulgaria. J Chemother 20, 593599.

Wachino, J., Shibayama, K., Kurokawa, H., Kimura, K., Yamane, K., Suzuki, S., Shibata, N., Ike, Y. \& Arakawa, Y. (2007). Novel plasmid-mediated 16S rRNA m1A1408 methyltransferase, NpmA, found in a clinically isolated Escherichia coli strain resistant to structurally diverse aminoglycosides. Antimicrob Agents Chemother 51, 4401-4409.

Wu, Q., Zhang, Y., Han, L., Sun, J. \& Ni, Y. (2009). Plasmid-mediated 16S rRNA methylases in aminoglycoside-resistant Enterobacteriaceae isolates in Shanghai, China. Antimicrob Agents Chemother 53, 271272.

Zacharczuk, K., Piekarska, K., Szych, J., Zawidzka, E., Sulikowska, A., Wardak, S., Jagielski, M. \& Gierczyński, R. (2011). Emergence of Klebsiella pneumoniae coproducing KPC-2 and 16S rRNA methylase ArmA in Poland. Antimicrob Agents Chemother 55, 443-446.

Zhang, Y., Zhou, H., Shen, X. Q., Shen, P., Yu, Y. S. \& Li, L. J. (2008). Plasmid-borne armA methylase gene, together with $b l a_{\mathrm{CTX}-\mathrm{M}-15}$ and $b a_{\mathrm{TEM}-1}$, in a Klebsiella oxytoca isolate from China. J Med Microbiol 57, 1273-1276. 